\title{
Aquilo que Não Se Pode Falar, que É Isso Preciso Dizer: a linguagem em Wittgenstein e Novarina
}

\author{
Lígia Souza de Oliveira \\ Universidade de São Paulo (USP) \\ E-mail: oli.ligia@gmail.com
}

O artigo "Aquilo que não se pode falar, é isso que é preciso dizer" a linguagem em Wittgenstein e Novarina faz parte da pesquisa de doutorado em elaboração na Universidade de São Paulo. O dramaturgo franco-suíço Valère Novarina afirma em sua obra teatral que a palavra opera a partir do conceito de chamamento. Para ele, a nomeação como linguagem ostensiva indicada por Santo Agostinho dá lugar ao processo provisório e transitório de relação entre a palavra e a significação, através do chamamento. Para aprofundar essa concepção, realizaremos neste estudo uma apresentação da obra do filósofo austríaco Ludwig Wittgenstein evidenciando uma ligação estreita entre a sua noção de jogos de linguagem e a concepção novariana de chamamento. Reconhecendo a relevância dos escritos de Wittgenstein para a filosofia da linguagem e a necessidade de aproximar suas conceituações da linguagem teatral, este artigo pretende apresentar conceitos chaves da segunda fase do filósofo e também contribuir e aprofundar o entendimento de algumas concepções teatrais e dramatúrgicas elaboradas por Novarina.

Palavras-chave

Valère Novarina; Ludwig Wittgenstein; dramaturgia contemporânea; filosofia da linguagem;
The article "What we cannot speak about is precisely what has to be said" the language in Wittgenstein and Novarina is part of the doctoral research in preparation at the University of São Paulo.The french-swiss Valère Novarina say in his plays that the word operatesfrom the concept of calling. To him, the nomination as ostensible language, indicated by Saint Augustine give place to the provisory and transitory process in the relation between the word and the signification, through the calling.To get deeper this conception, we will develop in this study a presentation of work the austrian philosopher Ludwig Wittgenstein evidencing a close connection between his language game's notion and the novarian conception of calling. Recognizing the relevance of Wittgenstein's writings to the philosophy of language and the need to approach his concepts of theatrical language, this article intends to present key concepts of the second phase of the philosopher and also to contribute and deepen the understanding of some theatrical and dramatic conceptions elaborated by Novarina.

Keywords

Valère Novarina; Ludwig Wittgenstein; contemporary dramaturgy; philosophy of language; 
Para iniciar a compreensão da obra dramatúrgica do franco-suíço Valère Novarinase faz necessário a compreensão da diferença dos termos mot e parole, que em francês designam respectivamente a palavra com enfoque no seu teor de significante, podendo ser substituída pelo termo vocábulo, e a palavra sendo utilizada de maneira mais abrangente, podendo também ser traduzida como discurso. Novarina numa entrevista concedida à tradutora brasileira Ângela Leite Lopes explica: "uma coisa interessante é que nem todas as línguas têm a palavra parole como oposta à palavra mot, porque em francês pode haver uma oposição entre mot, que é algo de seco, e parole, que é fluida" (NOVARINA apud ANGELA, 2001, p. 11 e 12). No português a tradutora transcreve a diferenciação nos correspondentes palavra (mot) e fala (parole).

Grande inventor de modos de pôr em tensão a língua francesa, Novarina acredita que a articulação das palavras - a comunicação - é a questão que enquadra e limita as vivências humanas:

Eis que agora os homens trocam entre si palavras como se fossem ídolos invisíveis, forjando nelas apenas uma moeda: acabaremos um dia mudos de tanto comunicar; nos tornaremos enfim iguais aos animais, pois os animais nunca falaram mas sempre comunicaram muito-muito bem. Só o mistério de falar nos separava deles (NOVARINA, 2009-1, p. 13).

Novarina nos convida, então, a perceber a palavra como fala, o que se relaciona com a invenção e a retirada do princípio designativo na referência aos objetos. $O$ autor elucida:

Falar não é comunicar. Falar não é trocar nem fazer escambo - das ideias, dos objetos - falar não é se exprimir, designar, esticar uma cabeça tagarela na direção das coisas, dublar o mundo com um eco, uma sombra falada; falar é antes abrir a boca e atacar o mundo com ela, saber morder. O mundo é por nós furado, revirado, mudado ao falar. Tudo o que pretende estar aqui como um real aparente pode ser por nós subtraído ao falar. As palavras não vêm mostrar coisas, dar-lhes lugar, agradecer-lhes educadamente por estarem aqui, mas antes parti-las e derrubá-las (NOVARINA, 2009-1, p. 14).

Esta é uma das abordagens da palavra que se faz necessário evidenciar na obra de Novarina: percebê-la enquanto fala e não enquanto comunicação. Como consequência dessa condição, cada estrutura linguística no texto do dramaturgo desarticula o que entendemos por realidade e nos propõe a construção de outras possibilidades de elaboração linguística de mundos. Através da desarticulação das palavras, os textos de Novarina criam, inventam possibilidades passageiras e transitórias de invenção de mundos.

Para dar conta dessa proposição acerca da palavra em Novarina encontramos uma pista em sua própria obra. Repleta de referências acerca da filologia, filosofia, linguística e literatura, Novarina aponta em seu texto Diante da palavra uma clara referência à filosofia elaborada por Ludwig Wittgenstein: "Aquilo que não se pode falar, é isso que é preciso dizer" (NOVARINA, 2009-1, p. 20).

O austríaco Ludwig Wittgenstein é um dos principais teóricos da filosofia da linguagem. Sua teoria é dividida em duas partes antagônicas. A primeira fase, representada principalmente pelo seu primeiro livro Tractatus lógico-philosophicus (2001), tenta responder como é possível falar sobre o mundo e como a linguagem opera para corresponder à realidade. Neste estudo entende-se que a realidade e a lingua- 
gem são construídas a partir da mesma lógica, sendo então a linguagem como uma permanente figuração da materialidade, das formas objetivas do mundo. Neste livro, o filósofo defende que uma palavra denomina, nomeia um objeto (WITTGENSTEIN, 2001, p. 63). Logo, as subjetividades que ele reúne - a ética, a estética e a religião, por exemplo - não podem ser afiguradas pela linguagem, existindo somente na forma dos fatos. Com isso, ele pode dizer: "o que não se pode falar, deve-se calar" (WITTGENSTEIN, 2001 , p. 129). Como já adiantamos, o dramaturgo franco-suíço, numa relação diretamente antagônica com a primeira fase de Wittgenstein, propõe a necessidade de utilização da palavra em outras possibilidades que não a objetiva, indicadora e comunicacional: "Aquilo que não se pode falar, é isso que é preciso dizer" (NOVARINA, 2009-1, p. 20). Essa visão novariana nos parece ser justamente a questão desenvolvida por Wittgenstein na segunda fase de seu percurso teórico, que encontramos, principalmente, no seu livro Investigações Filosóficas. Nesta fase, ele discorda da ideia platônica de que a linguagem foi criada para substituir o objeto. Formula que a nomeação não é a única possibilidade da linguagem, e que mesmo esta designação tem variações de acordo com a intenção, a entonação e outros, o que requer uma constante tentativa de alinhamento entre os pensamentos, os fatos e as proposições.

É a partir dessa relação que iremos desenvolver este artigo, tendo como foco 1) a apresentação da obra do filósofo austríaco (pouco utilizada pelos estudos teatrais) e os principais conceitos da sua segunda fase, ao mesmo tempo em que 2) coloca-a em relação com a obra de Novarina, discutindo mais a fundo as questões acerca da linguagem nos textos do dramaturgo francês.

\section{Dois Wittgensteins}

Boa parte da filosofia do século XX estava preocupada com o problema da linguagem. Ela dominou boa parte das reflexões filosóficas deste século e Wittgenstein foi fundamental neste processo, para ele, todo problema filosófico é, antes de tudo, um problema de linguagem (WITTGENSTEIN, 2001, 4.0031). É importante ressaltar que, quando se fala de Wittgenstein, não se faz referência apenas a um filósofo, mas no mínimo a dois. São duas visões que o filósofo elabora durante a sua vida, e o mais interessante é a percepção de que elas são opostas. O primeiro Wittgenstein é completamente diferente do chamado segundo Wittgenstein. Porém, mesmo que opostas, as duas teorias são extremamente importantes para o estudo da linguagem e influenciaram escolas filosóficas muito diferentes no decorrer do século XX, e ainda hoje o fazem.

Ludwig Josef Johann Wittgenstein nasceu em 26 de abril de 1889, iniciou seus estudos na engenharia em Manchester na Inglaterra, porém acabou por voltar-se para a filosofia a partir do contato com Bertrand Russel, já em Londres. De vida pessoal extremamente conturbada e temperamento difícil, Wittgenstein abandonou a filosofia de 1920 a 1929.

As duas teorias de Wittgenstein, apesar de antagônicas, tentam responder uma mesma pergunta: como é possível que os sons que emitimos se transformem em significação? O que é isso que chamamos de sentido? As respostas para estas perguntas podem ser encontradas primeiramente no livro Tractatus Logico-Philosophicus, que define o pensamento da primeira fase de Wittgenstein, e também no livro Investigações Filosóficas, que, junto com outros escritos do filósofo, marcam sua segunda fase. 
O que achamos extremamente necessário que se coloque na oposição entre as duas fases de Wittgenstein é justamente a sua concepção acerca da linguagem. Enquanto na primeira fase ela é analisada enquanto uma entidade, buscando sempre a sua essência e análise última, na segunda a linguagem é ressaltada enquanto uma atividade, e como tal, passível de transformação.

\section{Tractatus e a Aderência à Realidade}

A primeira fase de Wittgenstein está contida no livro Tractatus Logico-philosophicus. Conhecida como Atomismo Lógico, termo cunhado por Russel e radicalizado por Wittgenstein, esta filosofia considera a linguagem como proposições de nomes que se articulam com objetos da realidade, com possibilidades sintáticas que aderem à lógica do real. Estes nomes reproduzem as possibilidades combinatórias dos objetos, é uma relação de designação. A além disso, a linguagem está relacionada ao processo lógico da realidade e a sintaxe espeIha a sua estrutura.

Para Wittgenstein toda proposição da linguagem poderia ser transformada em uma proposição lógica. Dessa forma, ao analisar a proposição lógica se chegaria a uma síntese que representaria a essência da linguagem, seja qual for a proposição inicial. Esta análise revelaria que, assim como há um cerne dos materiais no plano da realidade, da mesma forma isto aconteceria na linguagem.

Essa adesão ao real é chamada de verificabilidade, na qual a linguagem somente poderia ser indicada como verdadeira ou falsa quando da verificação dessa proposição no mundo. Assim, o significado consiste na sua adequa- ção e, caso não correspondesse à realidade, seria considerada uma proposição falsa.

Portanto, nessa primeira teoria de Wittgenstein acerca da linguagem, o nome estaria designando um objeto, sendo uma proposição elementar (junção de nomes e conectivos) correspondente então à um estado de coisas. Já uma proposição complexa está sempre condicionada ao fato, à existência ou não de uma situação. A este processo de aderência à realidade chama-se de afiguração ou, ainda, de teoria pictórica.

Neste processo, a forma de um objeto, ou seja, a forma de realidade, deveria ser correspondente à forma da linguagem, chamada de forma de representação. Essas duas formas são o que garante a aderência, o isomorfismo linguagem-mundo. Porém, estas duas categorias não podem ser, elas próprias, uma afiguração da realidade. Caso realizássemos a análise da forma de representação, não chegaríamos a nenhuma proposição, e seria necessário a existência de uma outra linguagem para se afigurar a forma de representação dessa primeira linguagem, e assim sucessivamente. Portanto, essas duas categorias, juntamente com a ética e a religião, por exemplo, não podem nesta primeira fase de Wittgenstein, serem referenciadas através de proposições afigurativas. Isto é, nesta análise de Wittgenstein o que não pode ser dito, pode ser apenas mostrado. É nesta direção que Wittgenstein finaliza o seu primeiro livro "o que não se pode falar, deve-se calar" (WITTGENSTEIN, 2001, p. 129).

É a partir da oposição a esta afirmação que iniciamos o paralelo com a obra de Valère Novarina. O dramaturgo vai exatamente contra este pensamento e afirma que o ato de nomear é o grande mal do homem, pois utiliza a palavra como moeda de troca com a realidade. 
O grande ícone da nomeação, da designação, segundo o dramaturgo, é a comunicação:

\begin{abstract}
À imagem mecânica e instrumental da linguagem que nos propõe o grande sistema de mercado que vem estender sua rede sobre nosso ocidente desorientado, à religião das coisas, à hipnose do objeto, [...] a esse tempo no qual o materialismo dialético, desmoronado, dá passagem ao materialismo absoluto oponho nosso nossa decida em linguagem muda na noite da matéria de nosso corpo pelas palavras. (NOVARINA, 2009-1, p. 13).
\end{abstract}

Ou seja, a concepção de linguagem de Novarina parte justamente da oposição à linguagem designada ao mundo, conforme defende o Tractatus. Dessa forma, recorreremos à segunda fase de Wittgenstein para aprofundar o pensamento do dramaturgo.

\section{Santo Agostinho e a Linguagem Ostensiva}

Nas Investigações Filosóficas o teórico inicia o livro citando Santo Agostinho, enfatizando a sua visão sobre o aprendizado da linguagem. Neste trecho, Agostinho defende que a essência da palavra está, justamente, na forma como ele próprio, quando criança, aprendeu a utilizar a linguagem: "se os adultos nomeassem algum objeto e, ao fazê-lo, se voltassem para ele, eu percebia isto e compreendia que o objeto fora designado pelos sons que eles pronunciavam, pois eles queriam indicá-lo" (AGOSTINHO apud WITTGENSTEIN, 1991, $\S 1)$.

Essa citação vai ao encontro de toda a teoria defendida no Tractatus Logico-Philosophicus, que considera que a essência da palavra é a designação, a nomeação. Wittgenstein resume que "nesta imagem da linguagem encontramos as raízes da ideia: cada palavra tem uma significação. Esta significação é agregada à palavra. É o objeto que a palavra substitui"” (WITTGENSTEIN, 1991, §1).

Já adiantamos anteriormente que a essa ideia o filósofo se oporá em parte. A diferença das duas fases de Wittgenstein é que ele não mais acredita que esta seja a única forma de utilização da linguagem, ou ainda que esta seja a essência da palavra. Através de vários exemplos, que iremos indicar no próximo tópico, ele vai nos mostrando que a nomeação não dá mais conta da totalidade de possibilidade de utilização da linguagem. Para ele, a nomeação é apenas uma delas.

A impossibilidade de demonstrar através da lógica números brutos que contabilizassem um espaço, que trabalhassem com a medida, conforme nos evidencia Cuter no artigo Um Percursor dos Jogos de Linguagem, é justamente a questão que acaba por tensionar também a ideia de ensino ostensivo das palavras, ou demonstração ostensiva. Essa definição trata justamente na possibilidade de, através de três elementos - uma expressão demonstrativa, um gesto do enunciador e um objeto - permitir o aprendizado da linguagem (GLOCK, 1998, p.122). Facilmente usamos essa demonstração para ensinar crianças sobre as coisas do mundo.

Esse ensino ostensivo das palavras, pode-se dizer, estabelece uma ligação associativa entre a palavra e a coisa: mas o que significa isso? Ora, isso pode significar coisas diferentes; no entanto, pensa-se logo no fato de que, quando a criança ouve a palavra, a imagem da coisa surge perante seu espírito. Mas se isso acontece - é essa a finalidade da palavra? - Sim, pode ser a finalidade. (WITTGENSTEIN, 1991, §30) 
$\mathrm{O}$ que Wittgenstein quer demonstrar nesse trecho é justamente a ideia de que o ensino ostensivo é extremamente eficaz para a aprendizagem de certas possibilidades da palavra, mas relata justamente que esse ensino não é o único.

A definição do número dois "isto se chama "dois" - enquanto se mostram duas nozes - é perfeitamente exata. Mas, como se pode definir o dois assim? Aquele a que se dá a definição não sabe então, o que se quer chamar com "dois"; suporá que você chama de "dois" este grupo de nozes! - Pode supor tal coisa; mas talvez não o suponha (WITTGENSTEIN. 1991, 28).

Esse exemplo demonstra como a palavra não está relacionada somente ao ensino ostensivo, à associação com as coisas, principalmente certas palavras como hoje, não, justiça, ética e etc. Para Glock, além do fato de que nem todas as palavras podem ser definidas ostensivamente, Wittgenstein também acreditava que "amostras só determinam os significados dos signos porque as utilizamos como padrões de correção. O que determina o uso correto do signo explicado não é a amostra, mas o modo como a utilizamos para efeitos de explicação e correção" (GLOCK, 1998.p. 125).

\section{Jogos de Linguagem}

Em sua segunda fase, Wittgenstein acredita que o significado não é dado por um objeto ao qual a palavra estaria ligada, mas inversamente, seria dado a partir de regras específicas que utilizamos para inserir a palavra na nossa vida e fazer com que possamos nos relacionar com os objetos. Porém, estes objetos não possuem sintaxe pré-existente.
Em O Livro Azul, um dos primeiros escritos que Wittgenstein organizou ao opor-se drasticamente à sua primeira fase, ele inicia com a provocação "O que é o sentido de uma palavra?" (WITTGENSTEIN, 1992, p. 25). Essa pergunta é conduzida por todo livro e ousamos dizer que se trata da questão central desta segunda fase, quando o filósofo constrói relações menos rígidas com a lógica, admitindo a condição de permanente mudança da linguagem.

\begin{abstract}
As questões "O que é o comprimento?", "O que é o sentido?", "O que é o número um?" etc., causam-nos um constrangimento mental. Sentimos que para lhes dar respostas deveríamos apontar para algo e, contudo, sentimos que não podemos apontar para nada. (Enfrentamos uma das grandes fontes da desorientação filosóficas: um substantivo faz-nos procurar uma coisa que the corresponda). (WITTGENSTEIN, 1992, p. 25).
\end{abstract}

Durante todo o livro Wittgenstein nos apresenta uma série de palavras que, pelo mesmo motivo acima, não contêm um sentido ostensivo que possa dar cabo disso que a tradição filosófica apresenta como nomeação. No trecho abaixo Wittgenstein refere-se ao uso da palavra desejo:

No fim das contas não existe uma categoria definida de características que seja aplicável a todos os casos de desejo (pelo menos no sentido em que a palavra é habitualmente utilizada). Se, por outro lado pretendem dar uma definição do desejo, isto é, estabelecer um limite nítido, para o uso da palavra então são livres de o fazerem como quiserem; mas este limite nunca será inteiro coincidente com o uso real, visto que este uso não tem um limite nítido. (WITTGENSTEIN, 1992, p. 50). 
Para Wittgenstein não há um significado que seja indicado como o correto para cada palavra, e não há nenhum poder significativo escondido por trás delas, independente do processo de enunciação. Para cada palavra há diversas significações que são aplicadas de acordo com seu uso, tanto que as transformações da linguagem no cotidiano acabam por estender o campo de atuação da linguagem como um todo.

Ou seja, a segunda fase de Wittgenstein defende que o significado da palavra é maleável de acordo com o seu uso. Essas possibilidades de significação plural ele chama de jogos de linguagem, alegando que os sentidos das palavras são utilizados de acordo com as regras estabelecidas naquele instante em que ela é utilizada. O teórico esclarece:

Quantas espécies de frases existem? Afirmação, pergunta e comando, talvez? - Há inúmeras de tais espécies: inúmeras espécies diferentes de emprego daquilo que chamamos de "signo", "palavras", "frases". E essa pluralidade não é nada fixo, um dado para sempre; mas novos tipos de linguagem, novos jogos de linguagem, como poderíamos dizer, nascem e outros envelhecem e são esquecidos. (WITTGENSTEIN, 1991, §23)

O que é importante frisar neste trecho é que o entendimento de jogos de linguagem não pressupõe uma catalogação de possibilidades. Mesmo o autor listando algumas em seu livro, ele deixa claro que esses jogos serão sempre renovados e colocados em tensão de acordo com o contexto e a época.

É exatamente por isso que a ideia de significação verdadeira ou falsa, cunhado por Wittgenstein em sua primeira fase, não pode mais ser aplicada de maneira genérica nessa concepção não representacional da lingua- gem. Não há a possibilidade de afirmar se uma significação está correta ou errada sem considerar o contexto de sua enunciação. Por isso podemos crer que a utilização da linguagem é sempre cambiante, não pode se fixar permanentemente. A essa concepção Wittgenstein faz uma analogia com uma velha cidade, na qual o centro contém ruas e ruelas com casas antigas e novas, construídas em épocas diferentes, ao mesmo tempo em que novos bairros vão se construindo com ruas mais estruturadas e casas mais uniformes e regulares (WITTGENSTEIN, 1991, §18).

Wittgenstein ainda nos elucida sobre o possível relativismo dos jogos de linguagem: ele não é absoluto. Dentro de algumas formas de vida, dentro de algumas regras de uso pode-se sim corrigir ou justificar alguns jogos de linguagem. Algumas proposições podem ser questionadas por suas afirmações, corrigindo-as ou justificando-as. O que não é possível dentro dos jogos de linguagem é a contestação de uma forma de vida, de uma prática de linguagem.

Novarina, agora indo ao encontro da segunda fase de Wittgenstein, afirma:

Os vasos que comunicam, as máquinas que comunicam, os comunicadores que comunicam como máquinas, só dizem o que sabem. Da mesma forma os olhos, frente à imagem, só vêem o que vêem; a fala pelo contrário passa para além dela mesma, vem de mais longe que ela mesma, vai além do que ela pode dizer. Ela escuta o que não sabe; ela espreita. Nós falamos do que não podemos nomear. Muito precisamente cada palavra designa o desconhecido. Diga o que você não sabe. Dê o que você não possui. Aquilo do que não se pode falar, é isso que é preciso dizer. (NOVARINA, 2009-1, p. 20) 
Ou seja, Novarina concorda que a nomeação não dá conta da construção linguística como um todo pois ela se modifica a partir de vários fatores. O chamado toma o lugar da nomeação, pois ele opera no trânsito. Quando chamamos algo, ele se materializa naquele momento pois a coisa, o objeto, dá o seu ouvido ao chamado e não o contrário. Para Novarina, ao término do chamado a coisa já não mais existe, pois não se trata de nomeação. Segundo o dramaturgo,

nada é sem linguagem. Se a palavra sabe mais que a imagem, é porque ela não é nem a coisa, nem o reflexo da coisa, mas o que a chama, o que risca no ar sua ausência, o que diz no ar sua falta, o que deseja que ela seja. A palavra diz à coisa que ela está faltando $e$ a chama - e, ao chamá-la, ela mantém reunidos num mesmo sopro seu ser e seu desaparecimento. Como se esse movimento amoroso da fala tivesse chamado o mundo. O mundo aparece de um desaparecimento; é ao nos faltar que o real está diante de nós. $O$ universo não tem repouso. O espaço não é o campo da matéria, mas o teatro do drama da fala. Um túmulo vazio: toda matéria ficou ali. A matéria é porque a linguagem retirou-se dela. Em si mesma, a matéria não é nada. Ela é apenas uma linguagem feita de coisas. (NOVARINA, 2009-1, p. 22)

Toda essa citação aborda, antes de tudo, um entendimento novariano de que as coisas não existem anteriormente à palavra. Ao contrário, a linguagem é a origem. $E$, portanto, como nesse estatuto da palavra não comunicacional ela é momentânea, uma palavra inventa algo diferente a cada vez que é falada: "a palavra diz à coisa que ela está falando e a chama - e, ao chamá-la, ela mantém reunidos num mesmo sopro seu ser e seu desaparecimento" (NOVARINA, 2009-1, p.22). O chamado também opera nesse sentido, pois ele gera algo somente no momento em que chama, afora isso, as coisas não mais existem. Nada existe além da palavra, da fala, que em seu momento fugaz, inventa e destrói, instantaneamente, as coisas, os objetos, pois não os nomeia, não permanece enquanto identidade.

Portanto, a crise representacional da linguagem na obra de Wittgenstein aqui também pode ser indicada como a mesma crise posta por Novarina ao se relacionar com o teatro. A crise representacional da linguagem está no cerne da obra novariana que, conforme pretendemos demonstrar, utiliza-se de diversos jogos de linguagens para propor uma maneira particular de uso da linguagem, fora da comunicação e da nomeação como essência.

\section{Uso e Regras}

Para entender melhor o funcionamento dos jogos de linguagem, Wittgenstein nos assegura que a linguagem, nessa nova e cambiante configuração, deve ser analisada conforme o seu uso em seu contexto específico.

Para isso o filósofo nos dá o exemplo de um jogo de xadrez, ao supor que para que o jogo se realize plenamente, é necessário que se entenda o uso de cada peça, e não somente a sua simples nomeação: 'isto é um rei'. Apenas ao compreender como essa peça se comporta no jogo, sabendo todas as ações que pode realizar, é que se pode compreender o uso dessa peça. Da mesma maneira é a utilização da palavra. Não basta a nomeação, a vinculação de um som a um objeto, mas sim o entendimento do seu uso neste jogo determinado. Wittgenstein é claro: a significação de uma palavra é seu uso na linguagem (WITTGENSTEIN, 1991, §43). Portanto é importante também esclare- 
cer que, por exemplo, uma peça utilizada num jogo de dama, pode facilmente ser utilizada em diversos jogos de tabuleiro, trocando seu uso de acordo com as regras do jogo.

Para entender melhor os jogos de linguagem, também se faz necessário o entendimento de regra nas Investigações Filosóficas. A pesquisadora Karyn Cavalheiro nos questiona: "se a linguagem não tem mais o seu significado como que colado, [...] então é possível que eu use uma palavra qualquer para designar algo, já que seu significado será entendido no uso?" (CAVALHEIRO, 2006, p. 60). É nesse momento que Wittgenstein elabora de maneira mais clara a ideia de regra. Acompanhe o seguinte exemplo:

É como se olhássemos a cabine do maquinista de uma locomotiva: lá estão alavancas de mão que parecem mais ou menos iguais. (isto é compreensível, pois elas devem ser todas manobradas com a mão.) Mas uma é a alavanca de uma manivela que deve ser continuamente deslocada (ela regula a abertura de uma válvula); uma outra é a alavanca de um interruptor que tem apenas duas espécies de posições eficazes, ela é baixada ou levantada; uma terceira é a alavanca de um freio, e quanto mais forte for puxada, tanto mais fortemente freia; uma quarta, a alavanca de uma bomba, atua apenas quando movida para lá e para cá. (WITTGENSTEIN, 1991, §12)

A partir dessa situação podemos indicar que, mesmo no uso, uma palavra pode muito bem ser confundida com outra. Neste exemplo das alavancas, Wittgenstein nos elucida sobre a necessidade de que a regra do jogo esteja muito bem estabelecida para que a atividade possa ser executada de maneira clara. Porém essa regra nunca é algo que se encontra descrita: "uma regra não encontra emprego nem no ensino, nem no próprio jogo, nem está in- dicada num catálogo das regras" (WITTGENSTEIN, 1991, p. 34).

Obviamente que as regras de um jogo podem ser compreendidas através da observação. Porém, alguns detalhes sobre o funcionamento da linguagem devem ser apreendidos através de outras nuances que não somente a do jogo em si:

\begin{abstract}
Mas como o observador distingue, nesse caso, entre erro de quem joga e uma jogada certa? Há para isso indícios no comportamento dos jogadores. Pense no comportamento característico daquele que corrige um lapso. Seria possível reconhecer que alguém faça isso, mesmo que não compreendamos sua linguagem. (WITTGENSTEIN, 1991, §54)
\end{abstract}

Além dessa percepção acerca das entonações e sinais para além do uso da linguagem, Wittgenstein assinala também a necessidade de se perceber a regra como um convívio. Nesse caso a experiência com o jogo de linguagem será determinante para a efetividade do mesmo. A complexidade de certos detaIhes (gestos, tom da voz, ambiguidade do sentido da palavra e etc.) somente são possíveis a partir da vivência da linguagem. Neste caso se faz extremamente necessário que entendamos que a linguagem apreendida, o jogo de linguagem utilizado por certos jogadores está completamente aliado à sua forma de vida. Aprender uma linguagem está intimamente associado à vivência de uma forma de vida.

Quando aderimos necessidade de regras para concepção de um jogo de linguagem para a obra de Novarina, há ainda mais um tensionamento dessas questões. Como dissemos anteriormente, a obra de Novarina passa pela desconstrução da língua francesa na construção da langue de Novarina. Essa língua nos 
parece orquestrada de maneira diferente em cada obra, referenciando cada forma de vida ali apresentada. Porém, todas elas operam a partir da ideia de passagem.

Essa concepção, além de determinar uma entrada na relação da palavra com o corpo, inserindo uma concepção fisiológica da construção da linguagem, constrói também uma percepção de que o significado das palavras opera no trânsito, na passagem: "oponho o saber que nós temos, que existe, bem no fundo de nós, não algo do qual seriamos proprietários (nossa parcela individual, nossa identidade, a prisão do eu), mas uma abertura maior, uma passagem falada" (NOVARINA, 2009-1, p. 13).

Novarina, ao afirmar seu posicionamento contra a comunicação humana, contra a acepção de uma linguagem que atue na designação deste mundo ao colocar também a arte à serviço desta lógica humana, não propõe exatamente a transferência da comunicação por uma outra lógica de linguagem.

Não se trata da substituição de uma por outra. Trata-se, exatamente, da retirada da comunicação ordenadora para estabelecer diversos campos extremamente transitórios na construção da palavra. Com a instauração da palavra enquanto um chamado, a regra do jogo de linguagem presente nas obras de Novarina é a passagem, acepção de múltiplas e transitórias formas de significações da palavra.

A ideia de passagem opera no movimento, como se interessasse ao dramaturgo que a palavra não seja designada dentro de uma obra. A mesma palavra necessariamente atua de maneiras distintas dentro de um mesmo jogo de linguagem. Dessa forma, cada vez que uma palavra é dita, ela é ressignificada de acordo com o seu contexto. Interessa para Novarina mais o trânsito na construção de significações outras, do que a imposição de apenas um outro jogo de linguagem a partir de certas regras convencionadas. Em Novarina, a própria regra é tensionada a partir da acepção de passagem.

Portanto, podemos afirmar que a leitura da obra de Novarina tendo a passagem como regra do jogo de linguagem não está, por si só, colocando em tensão a proposição de regra em Wittgenstein? A nossa primeira reflexão indica que não, pois, as regras de Novarina enquanto passagem instauram em sua obra dramatúrgica uma regra subjacente que, junto com a acepção da palavra fisiológica, traz ao jogo de linguagem novariano uma potência imanente. Essa concepção inaugura outras formas de comunicação e propõe um jogo instaurado na palavra fora do logos, construída fisiologicamente e calcada no trânsito permanente dos significados.

\section{__ Pensamento e a Linguagem Privada}

Ao referenciarmos o uso e a necessidade de regras nos jogos de linguagem, um tópico importante emerge dessa condição. A linguagem enquanto atividade, produzindo significação a partir de seu contexto dá margem para a afirmação de que não há processo de significação sem o outro. A palavra somente ganha vida quando dita para alguém, afora isto permanece morta. Portanto, podemos declarar que não existe a possibilidade da existência de uma linguagem em um sujeito sozinho. Reconhecer que se faz parte de uma linguagem pública é o que delimita o ato de falar seguindo uma regra.

Dessa maneira, a Investigação Filosófica, trata também da oposição completa ao mentalismo subjetivista contido no Tractatus, no qual 
a ligação entre uma expressão e seu sentido é concretizada também por uma ação mental de querer-dizer. O solipsismo e o ceticismo também corroboram com essa acepção por haver uma concordância na existência de uma compreensão interior que, ao ser dominada, pode ser então transmitida ao outro.

Essa oposição ao mentalismo subjevista passa pela afirmação de que a compreensão da linguagem não se trata de um processo mental. Para vislumbrar melhor esse processo, devemos entender a acepção de pensamento segundo Wittgenstein: "pensar não é um processo incorporal que dá vida e sentido a falar e que poderia separa-se daquele" (WITTGENSTEIN, 1991, §39).

Por exemplo, quando nos perguntam quanto seria $2+2+2+2+2$, ou qualquer outra pergunta que nos obrigue a realizar cálculos, paramos por alguns segundos, executamos a operação mentalmente, para só então respondermos: 10. Wittgenstein afirma que o procedimento da linguagem não percorre o mesmo caminho, pois não necessitamos do processo de pensar para utilizarmos as palavras cotidianamente: "falar com ou sem pensamentos é comparável a executar com ou sem pensamentos uma peça musical” (WITTGENSTEIN, 1991, §43), ou seja, quando um bom pianista aperta a tecla dó, certamente ele não está pensando no exato momento 'estou apertando a tecla dó'.

Portanto, ao retirar o pensamento da mediação entre palavra e significação, Wittgenstein coloca a simples ação como motor necessário para a ativação da linguagem. Ou seja, as ações ou a forma de vida que os homens realizam/vivenciam num determinado contexto é o elo para o processo de significação. A teoria pragmatista da linguagem e do pensamento defendida nas Investigações refere-se para isso, à forma de ação que os homens têm em comum (a história natural da espécie, as formas de vida).

Apesar de usar recorrentemente a possibilidade da ação do pensamento na geração da linguagem, este conceito para Novarina ainda se encontra alinhado com a concepção de Wittgenstein. Para o dramaturgo o pensamento faz parte da construção de uma língua, porém, as suas considerações para este conceito não são muito diferentes do que pensa filósofo.

Para Novarina o pensamento se constrói a partir de dois aspectos: seu caráter corporal e sua adesão à linguagem enquanto chamado: "Pensar respirar: é soprar o espaço e levar ele em contradição. O pensamento não exprime mas dá passagem; ele levanta, desestabiliza. A fala sai vitoriosa pelo real, que ela fura" (NOVARINA, 2009-1, p. 17). Nesta elaboração, Novarina retira o caráter racional do pensamento e o coloca enquanto uma produção não logocêntrica, assim como a linguagem:

A fala é o elo que liberta. As palavras buscam o pensamento que as desfaz; o pensamento se liberta pelas palavras que captura: entre as palavras e a fala e o pensamento, há desde sempre um combate, uma luta que não para, em roda fala, ouve-se esse acerto e esse desacerto que é nossa libertação pelas palavras. Pensar é um rapto. Há perpetuamente uma cena de caça no espírito. (NOVARINA, 2009-1, p. 18)

Sobre a condição de rapto do pensamento tomamos ainda um outro trecho de Novarina:

O pensamento não utiliza as palavras não procura nunca as palavras, são as palavras que procuram, que vão no encalço do pensamento. Nós não despojamos das palavras ao falar. Aquele que fala, aquele escreve, é alguém que joga suas palavras como pedras divinatórias, porque teria algo a dizer, ele 
leva cada palavra a seu ouvido para ouvir, (NOVARINA, 2009-1, p. 20)

O rapto e as pedras divinatórias acabam por revelar como Novarina apreende o momento de articulação da palavra e da significação, portanto a mediação que se dá através do pensamento nunca está ligada à racionalidade. Mesmo considerando o pensamento no processo de construção da linguagem, essa percepção ainda vai ao encontro de Wittgenstein por considerar a própria fala a concepção da linguagem.

\section{Conclusão - Ação e Forma De Vida}

Para finalizar este estudo, compreendemos que dois conceitos de Wittgenstein fecham o elo de ligação com a obra de Novarina: ação e forma de vida. Esses dois conceitos resgatam o que Novarina defende como a atuação imperativa da linguagem: produção de universos múltiplos e transitórios, em detrimento à fixação e normatização da palavra humana. Para melhor entender essas elaborações de Novarina, vejamos a conceituação de Wittgenstein.

Sobre a ação que substitui a concepção de mentalidade subjetivista contida no Tractatus, referenciamos ainda a investigação da forma de vida que corresponde à existência daquela linguagem. Wittgenstein afirma que a palavra é antes de tudo, uma maneira de reconhecer uma forma de existência: "representar uma linguagem significa representar-se uma forma de vida" (WITTGENSTEIN, 1991, §19).

Por isso se se pode afirmar que a noção de verdadeiro e falso envolve a ideia anterior de uma concordância, será ainda mais correto dizer que se trata de algo mais forte do que a con- cordância e que é da forma de vida partilhada pelos indivíduos. 'Então afirmas que é a concordância entre as pessoas que decide o que é verdadeiro ou é falso?' - Verdadeiro e falso é o que os homens dizem; e é na linguagem que as pessoas concordam. Não se trata de uma concordância de opiniões, mas de formas de vida' (IF 241). (MARQUES, 2002, p.538)

Diante dessa primeira definição, apontamos no mínimo dois problemas ou duas condições acerca dessa concepção de linguagem enquanto forma de vida.

Primeiramente, é justamente pela concepção de semelhança de família que não se pode nunca apreender a totalidade de uma linguagem. A semelhança de família, definido por Wittgenstein como traços que aproximam ou distanciam alguns jogos, pode nos dar a ver algumas condições as quais uma linguagem exista em certo contexto, porém, a ela não se apresenta enquanto um todo fechado. A forma de vida que dá origem a uma linguagem não pode representar seu todo. A gramática não se deixa ver panoramicamente. O uso, por exemplo, de uma única palavra, não pode ser capturado ou descrito em sua totalidade.

Por outro lado, e também consequentemente, uma mesma regra de linguagem nem sempre será utilizada de maneira semelhante em todas as formas de vida. É claro que uma mesma palavra pode ser empregada de modo completamente diferente dependendo de seu contexto. Somente iremos apreender inteiramente uma regra se estivermos inseridos de forma profunda na situação de sua utilização. A forma de vida é a base para a construção da linguagem, e é exatamente por isso que ela é sempre uma atividade, uma ação.

Essa possibilidade diversa da linguagem, dentro ou fora de uma única de forma de vida 
é o que Wittgenstein nos revela na seguinte citação: "a linguagem é um labirinto de caminhos. Você entra por um lado e sabe onde está; chega por outro lado ao mesmo lugar e não sabe mais onde está". (WITTGENSTEIN, 1991, §203)

Essa ideia de que a linguagem cria mundos de acordo com os jogos, possui pode facilmente ser aplicada à literatura. Podemos, através de um olhar mais consensual, afirmar que cada obra literária possui em si um jogo específico com as palavras, que dentro de cada uma delas podemos encontrar um trato específico com a linguagem, o que a faz única e particular. Além disso, podemos tomar essa afirmação de maneira ainda mais radical. Ao referenciarmos, por exemplo, a obra de Guimarães Rosa, Grande Sertão: Veredas, podemos afirmar que existe ali a criação de uma língua específica que trata de, através da própria palavra, inaugurar um novo mundo. Ao utilizar-se de algumas lógicas da oralidade nordestina, acrescentando a ela novas possibilidades linguísticas, Guimarães Rosa apresenta uma língua particular que se justifica e se compreende a partir das regras criadas para aquele jogo, naquele livro. Da mesma maneira podemos citar James Joyce em Ulysses ao pôr em tensão a língua inglesa criando recursos como por exemplo o fluxo do pensamento.

É a partir dessa leitura acerca da literatura que chegamos na obra de Valère Novarina. Para o dramaturgo a ideia de que a linguagem é construtora de formas de vida, de mundos possíveis é o motor de sua escrita. É a partir dessa concepção de linguagem e da construção de um processo de significação no qual podemos afirmar que a linguagem é geradora de universos, de mundos autônomos e independentes da noção representacional, é que a obra de Novarina deve ser desbravada.

Para o dramaturgo, a linguagem está na origem dos objetos. Portanto, a forma como falamos opera, certamente, na forma de vida do indivíduo: "As palavras precedem as coisas; no começo há o chamado delas. No começo, não é o ser que é, mas o chamado. O próprio ser sempre foi apenas a primeira das coisas chamadas" (NOVARINA, 2009-1, p. 18).

Portanto, para Novarina, além da palavra ser a origem dos objetos ela também opera na construção de seres. O homem só é tido como tal a partir do uso que faz da linguagem. A medida em que a linguagem se recuse a configurar o formato humano, outras possibilidades de seres serão instauradas pela língua. Novarina aponta que o trabalho do ator é justamente a recusa do seu corpo humano e da linguagem ordenadora e logocêntrica no qual já está condicionado:
Tem um novo corpo que aparece em cena e que é submetido a outras leis materiais, uma espécie de aparição, um corpo carregado diante de si, cor- po exterior porque a imagem funda- mental que eu tenho é bem no fundo é que o ator carrega um corpo diante dele, ele carrega a linguagem diante dele. Ele apresenta o seu corpo. Ele é trans-humano. Ele sai da definição do homem. $\mathrm{O}$ ator vem destruir o ído- lo humano que se reconstitui o tempo todo, porque os homens são funda- mentalmente fabricantes de ídolos. $O$ teatro vem destruir as imagens pron- tas do homem. (NOVARINA apud LO- PES, 2011, p. 22)

Assim, ao afirmar a recusa do humano, o ator, bem como o próprio dramaturgo, dá lugar para a construção de outras humanidades, fora da identificação e da representação, configurando a palavra enquanto chamado e as regras de linguagem enquanto passagem: 
E tem também essa sensação, ao escrever (principalmente quando escrevi Vocês que habitam o tempo) que a linguagem é antropogênica. Você atira uma palavra, ou você quebra uma palavra e isso vai produzir homem. (NOVARINA apud LOPES, 2011, p. 23)

Portanto, a ideia de Wittgenstein de que a linguagem está vinculada diretamente à uma forma de vida, concorda com a visão de Novarina de que é através da palavra não comunicacional, da recusa ao logocentrismo e da afirmação da linguagem enquanto passagem, utilizando-se de jogos de linguagens passageiros e fugazes, que se faz é possível construir outras não-humanidades, revelando uma misantropia e uma linguagem geradora.

\section{Referências}

CAVALHEIRO, Karyn Cristine. Jogos de Linguagem e formas de vida na filosofia de Ludwig Wittgenstein. In: Tabulae: Revista de Filosofia. Curitiba: Gráfica Vicentina, v.1, n.1, p. 57-66, jan./jul. 2006.

CUTER, João Vergílio Gallerani. Um Percursor dos Jogos de Linguagem. In: Analytica Revista de Filosofia, vol. 9, n.2. Rio de Janeiro: 2005.

GLOCK, Hans-Johann. Dicionário Wittgenstein. Trad. Helena Martins. Rio de Janeiro, Jorge Zahar: 1998.

LOPES, Ângela Leite; KFOURI, Ana; REYS, Bruno Netto (org.). Novarina em cena. Rio de Janeiro: 7Letras, 2011.
MARQUES, António. A Crise da Linguagem Representacionalista em Wittgenstein. In: Revista Portuguesa de Filosofia. Ed. 58, n. 03, 2002.

MIGUENS, Sofia. L. Wittgenstein: o significado como uso: um estudo das Investigações Filosóficas (1953). In Filosofia da Linguagem - uma introdução. Faculdade de Letras da Universidade de Porto, 2007.

NOVARINA, Valère. Carta aos Atores e Para Louis de Funès. Trad. Ângela Leite Lopes, Rio: 7letras, 1999.

Diante da palavra. Trad. Ângela Leite Lopes, Rio: 7 Letras, 2009-1.

O ateliê voador e Vocês que habitam o tempo. Trad. Ângela Leite Lopes, Rio: 7Letras, 2009-2.

WITTGENSTEIN, Ludwig. Investigações Filosóficas. São Paulo: Nova Cultura, 1991.

O Livro Azul. Lisboa: Edições 70: 1992

Tractatus Lógico-philosophicus. São Paulo: EDUSP, 2001.

Recebido: 23/06/2017

Aprovado: 02/02/2018 